\title{
Diferentes Olhares da Comunicação no Turismo: entendendo três localidades paranaenses como destino e produto turístico ${ }^{1}$
}

\author{
Marcia Shizue Massukado Nakatania \\ Ewerton Lemos Gomes ${ }^{b}$ \\ Mylena Palazzo Nunesc
}

\begin{abstract}
Resumo
A comunicação de localidades como lugares de produção e consumo do turismo ocorre a partir de diferentes objetivos, sendo basicamente oriundas, de ações de promoção de organizações oficiais de turismo ou de comercialização de empresas privadas, como as operadoras e agências de viagem. 0 presente artigo discute as diferenças na comunicação de localidades por parte destas organizações, aplicando os conceitos de publicidade e propaganda para cada tipo de ação, quer somente promocional ou promocional e comercial. A pesquisa foi realizada a partir da análise documental de materiais promocionais (digitais e impressos) dos três principais destinos turísticos do Estado do Paraná (Curitiba, Foz do Iguaçu e Paranaguá). Como resultados concluise que a localidade é comunicada de duas formas distintas: como destino turístico e como produto turístico. Esta diferenciação tem implicações para o entendimento do emissor da mensagem (organismos oficiais de turismo ou empresas privadas), da estrutura da comunicação (promoção/marca ou promoção e comercialização/preço), e da apresentação da mensagem (publicidade ou propaganda).
\end{abstract}

Palavras-chave: Comunicação; Destinos turísticos; Produtos turísticos; Publicidade; Propaganda.

\begin{abstract}
Different Views of Communication in Tourism: Understanding three Localities in Paraná/Brazil as Tourism Destination and Tourist Product

The communication of localities as places of tourism production and consumption derives primarily from different organizations and aims (official tourism organisms with promotional actions or private companies such as travel agencies and the efforts of advertising). This article discusses the differences between how localities are communicated applying the concepts of advertising and publicity. The research was based on documentary analysis of printed and digital promotional materials of the three main tourist destinations of the State of Paraná: Curitiba, Foz do Iguaçu and Paranaguá.
\end{abstract}

1. Pesquisa contou com apoio financeiro do Conselho Nacional de Desenvolvimento Científico e Tecnológico (CNPQ) e do grupo de pesquisa Turismo, Tecnologia, Informação, Comunicação e Conhecimento - TURITEC

a. Doutora no Programa de Pós-Graduação em Administração -PPGADM da Universidade Federal do Paraná - UFPR. Docente nos cursos de Graduação em Turismo (CTUR/DETUR) e Mestrado em Turismo (PPGTUR) da Universidade Federal do Paraná - UFPR, Curitiba, Paraná, Brasil. E-mail marcia.nakatani@ufpr.br

b. Mestrando do Programa de Pós-Graduação em Turismo da Universidade Federal do Paraná (UFPR), Curitiba - Paraná - Brasil. E-mail: ewertonlegomes@gmail.com

c. Graduanda em Turismo da Universidade Federal do Paraná (UFPR), Curitiba - Paraná - Brasil. E-mail: mylena.trilhas@gmail.com 
Results shows that the locality is communicate with two distinct views and ways: as a tourism destination and as a tourist product. Thus, we conclude that for the same place it is possible to have different communication structures (only promotion or both promotion and commercialization aims), senders (who is speaking and its goals and interest) and message presentation (advertising or publicity).

Keywords: Communication; Tourism destination; Tourist product; Advertising; Publicity.

\section{Resumen}

Diferentes Puntos de Vista de la Comunicación en el Turismo: Entender trés Localidades del Paraná/Brasil como Destino Turístico y Producto Turístico

La comunicación de las localidades como lugares de producción y consumo turístico se deriva principalmente de diferentes organizaciones y objetivos (organismos turísticos oficiales con acciones promocionales o empresas privadas como las agencias de viajes y los esfuerzos de publicidad). Este artículo discute las diferencias entre cómo se comunican las localidades aplicando los conceptos de publicidad y propaganda. La investigación se basó en el análisis documental de materiales promocionales impresos y digitales de los tres principales destinos turísticos del Estado de Paraná: Curitiba, Foz do Iguaçu y Paranaguá. Los resultados muestran que la localidad se comunica con dos puntos de vista y maneras distintas: como destino turístico y como producto turístico. Por lo tanto, concluimos que para el mismo lugar es posible tener diferentes estructuras de comunicación (sólo promoción o ambos promoción y comercialización), remitentes (quién habla y sus objetivos e interés) y presentación de mensajes (publicidad o propaganda).

Palabras clave: Comunicación; Destino turístico; Producto turístico; Publicidad; Propaganda.

\section{INTRODUÇÃo}

O estudo da comunicação no turismo, neste artigo, procurou entender as diferenças na comunicação de localidades a partir da aplicação dos conceitos de publicidade e propaganda ao turismo. Assim, partiu-se da definição de localidade conforme apresentada pelo Instituto Brasileiro de Geografia e Estatística, como "[...] todo lugar do território nacional onde exista um aglomerado permanente de habitantes." (IBGE, 2016, não paginado), sendo assim e em específico para o turismo complementa-se que "[...] as localidades podem utilizar seus potenciais e as habilidades, capacidades e competências dos sujeitos/espaço que as integram para desenvolverem-se de forma endógena [...]" (Scótolo \& Panosso Netto, 2015, p.12).

Com efeito, a ideia de comunicar a localidade também é parte desse intuito em se desenvolver turisticamente, podendo seu entendimento estar ligado aos conceitos de publicidade e propaganda. Nesta investigação, procurou-se compreender a comunicação das localidades estabelecendo paralelos entre o emissor das mensagens (organismos oficiais de turismo ou iniciativa privada), entre as estratégias de promoção e as estratégias de promoção e comercialização, entre os conceitos de marca e de preço, sob a ótica da publicidade e propaganda (Gomes, 2011). 
Dessa forma o objetivo é entender a comunicação de localidades, como destinos e como produtos turísticos a partir da aplicação dos conceitos de propaganda e publicidade. Para tanto foram analisadas as ações de promoção das três principais localidades paranaenses, em relação ao turismo, feitos pelos organismos oficiais e públicos de turismo e as ações de promoção e comercialização realizadas pela iniciativa privada (operadoras e agências de viagem). A partir dessas análises o estudo buscou a diferenciação entre as formas como a localidade pode se comunicar e o entendimento de como a localidade é comunicada como destino turístico e como produto turístico.

Assim os tópicos seguintes versam sobre o entendimento e as diferenças entre publicidade e propaganda e de como ocorre a sua aplicação no turismo. Segundo Giacomini Filho (1998, p.62) "[...] tal relevância, talvez, se deva ao fato de que o conceito de publicidade se confunde com o de marketing, algo que também é comum no turismo. ". Cabe destacar que o estudo de Loda, Norman e Backman (2007) sobre a aceitação da mensagem publicitária ou da propaganda, destaca a ideia de diferenciação conceitual entre publicidade e propaganda concluindo que a sequência de apresentação das mensagens tem impacto no processamento desse conteúdo e que a propaganda é um elemento importante para o marketing turístico.

\section{Publicidade e Propaganda (Advertising and Publicity)}

Para a compreensão de conceitos relacionados às ações de comunicação no turismo, partiu-se do entendimento de Sandman (2007, p.10) para definir os termos publicidade e propaganda. Para o autor "[...] publicidade é usada para a venda de produtos ou serviços e propaganda tanto para a propagação de ideais como no sentido de publicidade. Propaganda é, portanto, o termo mais abrangente e o que pode ser usado em todos os sentidos.".

A diferenciação entre os conceitos de publicidade e propaganda também foi objeto do estudo de Gomes (2001, pp.5-7), em que apresenta que "[...] a publicidade, atualmente, evoluiu e já não faz isso com qualquer tipo de notícia ou anúncio, e sim apenas com aquilo que é estritamente comercial, ou seja, faz com o objetivo de atrair compradores [...] estando correlacionada a ideia de venda e comercialização de produtos". E, por sua vez considera que a propaganda, “[...] no terreno da comunicação social, consiste num processo de disseminação de ideias através de múltiplos canais [...]", remetendo à promoção de ideias e bens intangíveis.

Destarte a publicidade tem como preceito básico, “[...] qualquer forma de divulgação de produtos ou serviços, através de anúncios geralmente pagos e veiculados sob a responsabilidade de um anunciante identificado, com objetivos de interesse comercial.". (Rabaça \& Barbosa, 1987, p.481). Nesta definição observa-se o caráter comercial da publicidade, também presente no entendimento de Gomes (2011).

Para Muniz (2004, p.2), “[...] a publicidade contemporânea mitifica e converte em ídolo o objeto de consumo, revestindo-o de atributos que frequentemente ultrapassam as suas próprias qualidades e a sua própria realidade." Nesse ponto 
entende-se ainda que a publicidade é basicamente definida como uma estratégia para se vender um produto ou serviço. A diferenciação da publicidade para a propaganda é explorada por Muniz (2004, p.:5) ao conceituar que o princípio desta é "[...] propagar ideias, crenças, princípios e doutrinas."

No turismo, o uso deste conceito se aplica ao incentivo a conhecer alguma localidade, como Guardani, Aruca e Araújo (1996, p.23) apontam ao afirmar que a propaganda é aplicada quando uma pessoa que visitou um lugar faz propaganda, positiva ou negativa do local após conhece-lo, para outra pessoa. Já Muniz (2004) traz em sua interpretação, que, atualmente, a publicidade não possui o interesse de divulgação de qualquer coisa, mas possui caráter estritamente comercial, tendo como objetivo atrair consumidores.

Assim a propaganda, conforme Gomes (2011, p.115) refere-se à utilização para a propagação de ideias, conhecimento e teorias, tendo como características a capacidade informativa, a força persuasiva e o caráter ideológico. Ao se analisar a diferença entre publicidade e propaganda, considera-se que a publicidade está em um âmbito bastante comercial de produtos e serviços (Rabaça \& Barbosa, 1987; Nunes Junior, 2001; Muniz, 2004; Gomes, 2011) e a propaganda é utilizada com o intuito de disseminar ideias ou conceitos (mais abstratos) (Rabaça \& Barbosa, 1987; Nunes Junior, 2001; Muniz, 2004; Gomes, 2011).

Após o entendimento sobre estes dois macro conceitos, esta investigação focou na diferenciação dos processos presentes na comunicação de uma localidade através da aplicação dos conceitos de publicidade e a propaganda às mensagens veiculadas pelos canais e emissores selecionados.

\section{COMUNICANDO A LOCALIDADE COMO DESTINO TURÍSTICO}

O destino turístico como "fenômeno exclusivo do turismo" (Timón, 2004) e componente da cadeia produtiva do turismo, possui diferentes definições. Considerando sua condição de localidade, Bull (1994 citado por Corner, 2001, p.13) afirma que o destino turístico é o "[...] país, região ou cidade para onde se dirigem os visitantes, tendo-os como principal objetivo."

De outro modo, Cooper et al. (1993) enfatizam o destino turístico como uma área onde se concentram equipamentos, serviços e estruturas para satisfazer as necessidades dos turistas. Componente fundamental para a prática do turismo e ponto de concentração de atrativos e serviços o destino turístico também é considerado "[...] um conjunto que contém várias organizações e indivíduos que colaboram e competem na oferta de uma variedade de produtos e serviços ao turista." (Dias \& Cassar, 2006 citado por Madeira, 2010, p.10).

Como agente motivador para a realização de uma viagem, o destino turístico pode ser trabalhado, conforme aponta Marques (2005, p.17), como um "[...] espaço geográfico, com características próprias diferenciadoras, [...], constituindo um pólo de atracção de visitantes e possibilitando o desenvolvimento de uma, ou mais, formas de turismo.".

O destino turístico é compreendido como um desdobramento maior de todo o sistema turístico, ou ainda como local onde ocorrem as interações dos turistas com outros elementos da oferta comercial (alojamento, alimentação, atividades 
de lazer, transporte entre outras) e os produtos livres, elementos de promoção do destino, ou seja, sem preço, a paisagem, a tradição, o clima, a hospitalidade, a cultura etc. (Neves, 2007).

Considerando tais abordagens, nota-se que o destino se configura como uma localidade e/ou região em específico para onde os turistas se dirigem seja por seus atrativos ou pelo conjunto de elementos existentes nessa localidade (Corner, 2001; Madeira, 2010; Marques 2005; Timón, 2004; Neves, 2007). É nesse ponto, ou seja, a partir de sua definição que se considera a complexidade da promoção da localidade como destino turístico, uma vez que corresponde não apenas a um conjunto de atrativos, mas também à junção destes com equipamentos e serviços de infraestrutura local (acesso rodoviário/aéreo), com equipamentos/serviços de apoio ao turista, comunicação, serviços de translado, apresentações artístico / culturais, ou seja, elementos que facilitem a permanência do visitante no local.

Esse conjunto de elementos conformam uma marca para essa localidade, ou seja, uma forma de valoração não monetária; e que pode ser considerada equivalente ao preço ou ao processo de precificação do produto turístico. Chias (2005, p.113) considera que "[...] a marca, em primeiro lugar, é também um sinal que identifica um conjunto de sinais de identidade, é o principal valor de qualquer produto, empresa ou lugar no mercado [...].". Por este fato, considera-se a marca elemento essencial para a promoção da localidade como destino turístico, e nesse ponto a propaganda é a estratégia que se adequa e tem sido utilizada na comunicação da localidade como destino turístico.

O destino turístico, por meio da ação (conjunta ou não) da iniciativa privada e do poder público, configura sua identidade, que se tornará a base de sua promoção turística. Já a imagem do destino, conformada pela percepção dos turistas, é pautada pelas experiências destes na localidade e como percebem a identidade criada pelas ações promocionais transformando-as em uma imagem que reflita seus interesses (Cruz, Gonçalves, Mendes Filho \& Santos, 2008; Costa, Soares \& Emmendofer, 2011; Echtner \& Ritchie 2003).

De maneira geral, no Brasil, a promoção de um destino turístico é uma função delegada aos organismos públicos, tais como secretarias estaduais e institutos municipais de turismo, como a TurisRIO (RJ), SPTuris (SP), Instituto Municipal de Turismo de Curitiba. Em outros países como Estados Unidos da América e países situados na Europa, a promoção dos destinos turísticos concentra-se na iniciativa privada, um exemplo dessa configuração promocional é citado por Marques de Sousa e Massukado-Nakatani (2015, p.3) ao exemplificar essa situação: "[...] o marketing norte-americano é feito pelo setor privado e pela Travel Industry Association (TIA), uma organização de comércio sem fins lucrativos.".

Assim, estes órgãos constituem a base promocional dos destinos e o poder público fica encarregado do planejamento de ações, executadas, muitas vezes, em parceria com a iniciativa privada.

Visto que um destino pode se promover por meio de iniciativas isoladas quer oriundas de ações públicas e/ou privadas, a promoção deve corresponder à realidade de seu entorno, sendo responsável por levar em consideração as opiniões dos residentes e empresas que atuam na localidade. Uma vez que, o enfoque principal é a satisfação dos turistas, o marketing também aponta para a necessidade de satisfação e desejos dos residentes e das empresas envolvidas com o turismo (Cruz, Gonçalves, Mendes Filho \& Santos, 2008). 
A partir desse entendimento de promoção da localidade como destino turístico tem-se no marketing de uma localidade diferentes premissas, tais como: a) elaborar a composição correta de atrações e serviços da comunidade; b) estabelecer incentivos atraentes para os atuais e possíveis compradores e usuários de bens e serviços; c) fornecer produtos e serviços locais de maneira eficiente; e d) promover os valores e imagem do local de forma a conscientizar os possíveis usuários das suas vantagens diferenciadas (Costa, Soares \& Emmendofer, 2011). Levando em conta a multiplicidade de relações que são desenvolvidas na localidade e as mais diversas interações sociais entre os atores , o destino torna-se um atrativo institucional, uma vez que, essa institucionalidade provém da soma de ações de promoção realizadas pelo poder público e da interação entre público e privado.

Dessa forma, o destino promove a imagem turística, suas características físicas, sociais e sua hospitalidade. Promove-se uma representação da imagem do destino considerando o contexto e a soma das atividades que podem ser realizadas na localidade, dos serviços e equipamentos ofertados aos turistas, (permeados pela imagem construída pelas ações promocionais).

A promoção da localidade como destino turístico considera a soma de atrativos, de equipamentos e da infraestrutura básica e de apoio às atividades turísticas. Assim, "[...] a imagem de um destino deriva de um grande espectro de informações que envolvem aspectos históricos, políticos, econômicos e sociais." (Echtner \& Ritchie, 2003, P.4).

Corroborando essa visão de soma e articulação interinstitucional para a promoção de uma localidade, Morrison (2013, p. 294), nos diz

eles (destinos) não são produtos individuais, mas sim um amálgama de produtos e serviços sob diferentes posses. [...] apresentam várias dimensões, incluindo atrações e eventos, instalações, transporte, infraestrutura e recursos de hospitalidade. Todos estes elementos diferentes precisam ser integrados sob uma única marca/ promoção (Morrison, 2013, p.294).

Seguindo a lógica de Morrison (2013), a promoção de uma localidade volta-se a tudo que a compõe, assim, o destino é promovido de forma geral e não um atrativo em especifico. Pimentel, Pinho e Vieira (2006, p.287), destacam que “[...] o turismo, em alguns destinos, é ainda interpretado como uma atividade de autodesenvolvimento e com a concorrência do mercado turístico essa visão deve, o quanto antes, ser alterada., para que o mesmo não se torne mais um "produto turístico" vinculado a uma localidade.

A localidade é promovida institucionalmente com a finalidade de desvincular-se do conceito tradicional da comercialização e, "[...] para que isso aconteça, é importante ter uma imagem atraente e, consequentemente, obter destaque em meio a tantos outros locais que desejam se promover." (Echtner \& Ritchie, 2003, P.6). Com efeito, entende-se que as estratégias de divulgação para os mercados estão pautadas em ações que demonstrem o quão diferenciado pode ser a visitação ao local e o quanto essa visita agregará aos visitantes. Echtner e Ritchie (2003, p.4), destacam que "[...] o cliente precisa ter uma experiência única no ato 
de consumo, o que envolve diversos fatores, tais como aspectos funcionais (clima, preço, atrações naturais, por exemplo) e psicológicos (segurança, pobreza, qualidades dos serviços, fama, entre outros).."

Parafraseando Almeida (2005), testemunha-se que o parecer é mais importante do que o ter ou ser e, que os destinos devem mostrar ao seu público de interesse as qualidades da localidade que promove, interferindo de forma crescente e sutil na modelagem do imaginário e da subjetividade desse público.

\section{COMUNICANDO A LOCALIDADE COMO PRODUTO TURÍSTICO}

O turismo é atividade que ocorre a partir do deslocamento de pessoas. Para isso, entende-se que existe um fator motivacional que varia de grupo para grupo e pode ser similar entre eles, assim entender os públicos e os determinantes motivacionais é essencial para o desenvolvimento do produto turístico. Segundo o Ministério do Turismo são as características inerentes à oferta que determinam a imagem de um roteiro e embasam a formatação de produtos turísticos, estando sempre coligadas ou em função da demanda (Brasil, Ministério do Turismo, 2006).

O produto turístico é definido como um "[...] conjunto de bens e serviços que são utilizados para o consumo turístico por determinados grupos de usuários." (Organização Mundial do Turismo, 2001, p.290), ou ainda como "[...] uma proposta de viagem fora do lugar de residência habitual, estruturada através dos recursos, à qual se incorporam serviços turísticos: transporte, alojamento, guias de viagem, serviços de alimentação, etc." (EMBRATUR, Plano Aquarela, 2003-2006).

Sendo assim, os produtos turísticos são influenciados pelas características da demanda e englobam o que a localidade oferece, podendo configurar-se em atrativos e bens comercializados, como por exemplo, suvenires, ou ainda incluir os serviços disponibilizados, passíveis de precificação, pois segundo Middleton e Clarke (2002, p.96) "[...] o preço denota os termos publicados ou negociados da transação de troca de um produto entre um produtor [...] e clientes [...]", o que denota a aplicação do conceito de publicidade à localidade, ao se associar a comercialização ao preço do produto.

Entretanto, para que um produto possa ser comercializado deve-se ter em mente que o turismo, é uma atividade econômica que pertencente ao setor terciário, de comércio e serviços, e assim sendo classificado a partir de três fatores: i) uso excessivo de recursos humanos, ii) grande diversidade de oferta e iii) prestação de serviços intangíveis (Serviço Brasileiro de Apoio às Micro e Pequenas Empresas, 2008). Este último fator, caracteriza o turismo como um bem intangível e direciona as ações de comunicação para fundamentos provenientes do marketing de serviços e do marketing de lugares, que são os tipos mais frequentes e considerados para a promoção de bens intangíveis (Kotler, 2000; Petroski, Baptista \& Maffezzolli, 2013).

Sobre o marketing de lugares, Petroski, Baptista e Maffezzolli (2013) argumentam que esse entendimento incorpora o desenvolvimento local, pois, espaços que eram utilizados somente como moradia, hoje podem ganhar a imagem de "lugar-produto". Dessa forma o objetivo do marketing de lugares é "[...] projetar 
um lugar de modo que satisfaça as necessidades de seus mercados-alvo." (Kotler et al., 2007, p.148) ou seja, contribuindo para a imagem de um destino tornar-se desejável para a demanda.

O que torna a localidade um produto, além da comercialização dos produtos, atrativos e serviços disponibilizados no local, é a articulação de diferentes fatores indispensáveis que tornam o destino comercializável. Gândara (2007) argumenta ainda que, um desses fatores são as ações comunicativas que tem relação direta com a imagem dos destinos turísticos.

\section{MÉTOdos}

Este estudo de caráter exploratório-descritivo possui viés qualitativo tendo em vista o processo de análise dos dados, pois de acordo com Dencker (2001, p.129) esses procedimentos de pesquisa "também denominados [...], de desk-research, [...] utilizam uma grande quantidade de dados de fontes secundárias.". Dessa forma o estudo utilizou os materiais promocionais das cidades para analisar e compreender a diferenciação entre a localidade como produto e a localidade como destino, conforme discutido teoricamente na revisão de literatura.

A coleta de dados bibliográficos e documentais ocorreu durante um ano (entre Agosto de 2013 a Julho de 2014) e foi subdivida em duas frentes: 1) coleta de dados junto aos organismos oficiais de turismo das cidades e, 2) coleta de dados em operadoras que comercializavam as cidades².

Os materiais analisados provindos do poder público (OOT) foram coletados por meio de saídas a campo aos postos de informação turística (PIT's) e junto à Secretaria de Turismo do Estado do Paraná (SETU/PR), num total de 32 documentos (flyers, folders e mapas informativos e pictóricos), e 14 de prints de sites institucionais e de programas de divulgação oficiais e redes e mídias sociais. Já os materiais promocionais da iniciativa privada, provem de newletters enviadas por e-mail a partir de inscrição nos sites das operadoras (somente três operadoras encaminharam newsletter), e de prints desses sites (foram coletadas todos as informações sobre as localidades em todos os sites das operadoras, sendo no mínimo um print por operadora).

Dessa forma foi possível analisar os elementos em destaque destas duas iniciativas (organizações oficiais de turismo e empresas privadas do trade turístico) a fim de descrever as características nestes processos e diferencia-los frente aos objetivos da pesquisa. Para que os dados fossem analisados utilizou-se uma ma-

2. As 15 operadoras foram selecionadas a partir da lista de operadoras da Associação Brasileira das Operadoras de Turismo - BRAZTOA; no segundo recorte foram selecionadas 44 operadoras que comercializavam o Paraná como destino, entretanto, após visitar os sites destas operadoras, algumas foram descartadas por não apresentarem sites ativos (fora do ar); no terceiro recorte foram selecionadas as operadoras que comercializavam pelo menos um dos destinos turístico escolhidos para a pesquisa (Curitiba, Foz do Iguaçu ou Paranaguá/Ilha do Mel), assim foram selecionadas 18 operadoras. 0 último recorte foi realizado com base no sistema de cadastro de pessoas físicas e jurídicas que atuam no setor do turismo - CADASTUR, restando 15 que estavam com seu cadastrado atualizado no Ministério do Turismo; dentre as quais todas comercializavam Foz do Iguaçu, nove comercializavam Curitiba e somente duas comercializavam a Paranaguá/Ilha do Mel. 
triz de análise de conteúdo elaborada para um projeto desenvolvido no grupo de pesquisa TURITEC na Linha de pesquisa Turismo e Comunicação ${ }^{3}$, a matriz foi aplicada para ambos os materiais, para que as diferenciações entre os processos de promoção e, promoção e comercialização pudessem ser feitas ao final do trabalho.

A matriz foi desenvolvida como uma planilha, composta por três seções de análise: informações gerais sobre o material (descritivo), características textuais e características das imagens. No campo das informações gerais, os seguintes dados foram identificados: data de acesso/envio; identificação da operadora/00T; localidade promovida/comercializada; se promove/comercializa outro destino no mesmo material; meio de distribuição; tipo do material (se print de sites ou material impresso/digital); título; e idioma. Nas características textuais foram identificados: a) o texto principal do material; b) o texto secundário (se houvesse); c) informações turísticas (se disponibilizava e que tipo); d) sugestão de locais a visitar/o que fazer? (atrativos, caracterizados em gastronomia, evento, patrimônio, parques naturais, praias/lagos/rio, esportes, equipamento de lazer e recreação, ou outros); e) informações de contato; f) informações gerais (localização, indicação de modais); g) informações sobre comércio local; h) informações sobre preço e valores. Nas características da imagem, foram identificadas: a) Imagem Principal do Material (destino; segmento; atrativo; roteiro; evento; meio de hospedagem; transporte; equipamentos de lazer e recreação; serviço de alimentos e bebidas; Não possui; outros); b) Imagem Secundária do Material; e c) Existência de mapa ou croqui da localidade.

A análise de conteúdo dos materiais considerou as etapas estipuladas por Bardin (2011), referentes à pré-análise (sistematização da hipótese de pesquisa oriunda da revisão de literatura e definição de conceitos, seleção dos documentos e organização do material para análise); exploração do material (análise de cada documento, a partir da codificação na planilha das informações gerais, características textuais e de imagem); e tratamento dos resultados obtidos, inferência e interpretação (dados da planilha foram aglutinados de forma a evidenciar as diferenças entre os documentos confeccionados pelos órgãos oficiais de turismo dos produzidos pelas operadoras). É importante ressaltar que os conceitos de publicidade e propaganda foram abordados voltando o foco da investigação para as organizações oficiais de turismo e as entidades privadas do trade turístico (operadoras de turismo). A aproximação dessas etapas de pesquisa permitiu a discussão dos conceitos de publicidade e propaganda no turismo, auxiliando os pesquisadores a compreender a aplicação dos conceitos dentro da atividade turística.

3. O TURITEC surgiu em 2008 e foi registrado como grupo de pesquisa no CNPq em 2014, funcionando como um ambiente didático-pedagógico vinculado ao Departamento de Turismo da Universidade Federal do Paraná. A linha de pesquisa Turismo e Comunicação reúne pesquisadores doutores e mestres e discentes de graduação e mestrado que desenvolvem pesquisas relacionados às estratégias de comunicação no turismo. A matriz de análise utilizada foi desenvolvida pelos pesquisadores do TURITEC para o projeto de pesquisa Acompanhamento e avaliação de projetos, obras e serviços destinados à Copa do Mundo 2014 em Curitiba - Paraná e seus legados e oportunidades (Subprojeto Turismo), referente ao Edital do CNPq de Encomendas COENG Copa do Mundo 2014. 


\section{Resultados e Discussões}

Com a análise dos materiais promocionais das organizações oficiais de turismo e das operadoras (empresas privadas), ficou evidente a diferença entre as estratégias de comunicação localidades, quer como destino turístico ou como produto turístico. A partir da análise dos materiais selecionados foi possível observar que tanto o setor público quanto a iniciativa privada fazem o uso da informação para promover as localidades de Foz do Iguaçu, Paranaguá/Ilha do Mel e Curitiba. No entanto, apesar de ambos utilizarem o mix de marketing na teoria, o enfoque dado à promoção por estes dois entes é diferente na prática do uso da informação.

Observou-se que a dinâmica promocional das organizações governamentais difere em alguns pontos da estratégia utilizada pelas operadoras e agências de turismo quando da comunicação da localidade. Conforme Morrison (2013), nos organismos oficiais de turismo, a estratégia de promoção apresenta um caráter unilateral e sem enfoque mercadológico, isto é, estas organizações não tem pretensão de vender a localidade, sua energia e esforços promocionais centram-se na propagação de mensagens relacionadas à imagem do destino e à experiência ou segmento de turismo (cultural, sol e praia, lazer, negócios etc.).

Dentre os 32 materiais institucionais (quinze de Curitiba, dois de Foz do Iguaçu, nove de Paranaguá/Ilha do Mel e seis materiais gerais sobre o estado) e 14 prints dos sites e campanhas oficiais (cinco de Curitiba, três de Foz do Iguaçu e seis de Paranaguá/Ilha do Mel), coletados e analisados, nenhum apresentou enfoque na venda ou publicidade (e.g. sugestão de precificação, estabelecimento comercial, passeios pagos, serviços turísticos terceirizados etc.).

Os textos e imagens utilizados pelas organizações governamentais nos materiais promocionais (flyers, folders e mapas informativos e pictóricos) apresentavam um cunho informativo, isto é, voltados para a divulgação de conteúdos explicativos e utilitários, tais como: história do local, curiosidades sobre o destino, serviços públicos (linhas e horários de ônibus, telefones úteis e contato dos PIT's). As imagens, em sua grande maioria, destacavam cenários turísticos e atrativos com grande apelo comunicativo (e.g. Museu Oscar Niemeyer, em Curitiba; Cataratas do Parque Nacional do Iguaçu, em Foz do Iguaçu; e a Ilha do Mel, em Paranaguá). Algumas destas inferências podem ser observadas nas figuras (1 e 2) 
Figura 1: Print - Paraná Turismo

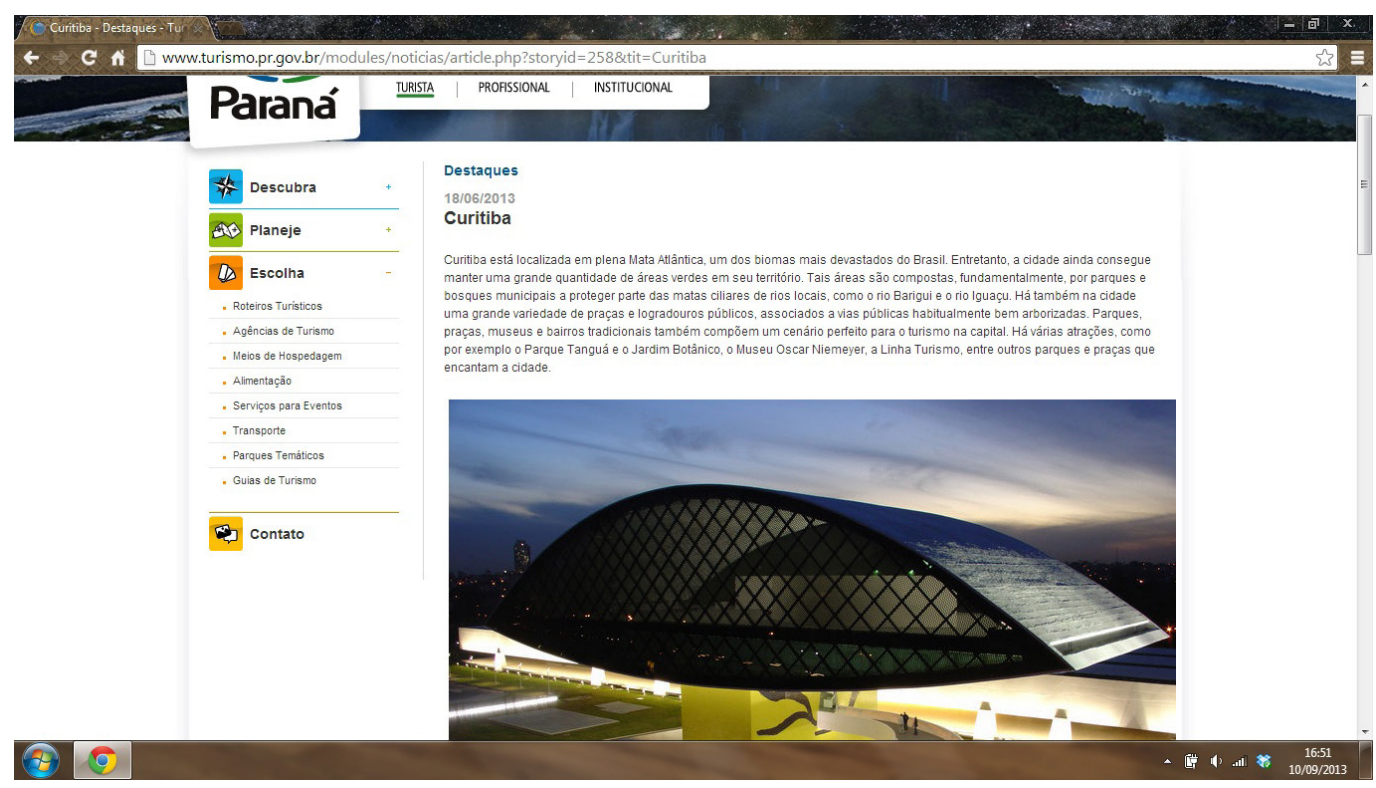

Fonte: Paraná Turismo (2013)

Figura 2: Prazer em Conhecer - Cataratas do Iguaçu

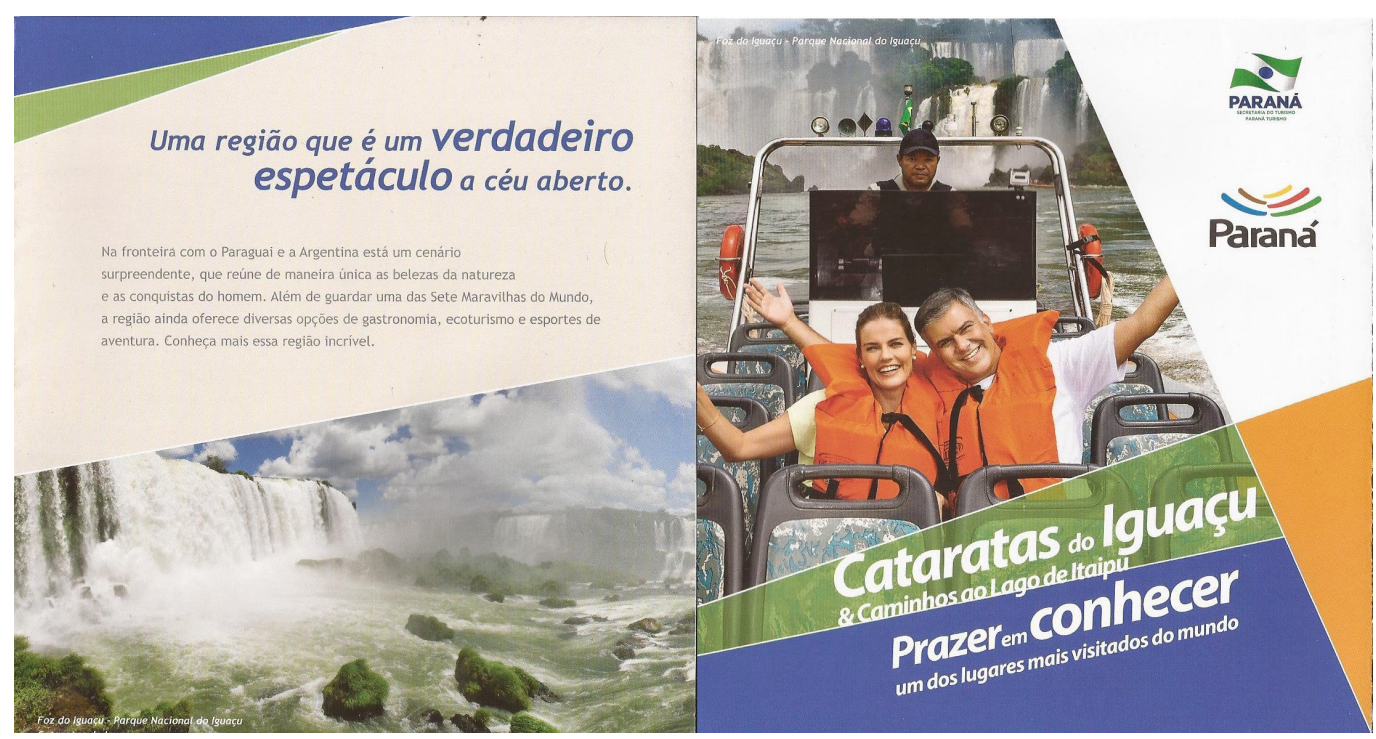

Fonte: Secretaria Estadual de Turismo do Paraná (2013)

Assim as organizações oficiais de turismo procuram promover o destino através da propagação de uma imagem idealizada e informações relativas aos seus atrativos (Echtner \& Ritchie, 2003), aderindo à sua finalidade de atrair os turistas e gerar divisas a partir de impostos ou taxas de permanência oriundas da atividade.

Cabe observar que a mesma dinâmica (informacional/propagandista) foi encontrada em todos os outros materiais e prints analisados. A ausência de preços e informações comerciais são duas das principais características que podem ser citadas ao diferenciar as estratégias de propaganda e publicidade. Tal dinâmica 
informacional/propagandista corrobora a hipótese de que existem diferenças entre a promoção de uma localidade por parte das organizações públicas (destino) e iniciativa privada (produto).

O setor público procura propagar a ideia da localidade como experiência no sentido da totalidade da viagem e da localidade como uma ideia com a intenção de atrair turistas e gerar fluxo para a localidade. Com o aporte da revisão bibliográfica é possível associar essa abordagem promocional à propaganda caracterizando a localidade como um destino turístico. Assim, para os organismos oficias de turismo, a aplicação da comunicação ocorre de forma unilateral, sem dar enfoque ou priorizar algum setor ou atrativo, caracterizando a localidade como um destino turístico. Com efeito o processo de propagação de ideias, usos, costumes e atratividade da localidade tem enfoque na propaganda e, essa comunicação é o que caracteriza promover a localidade como um destino turístico. Destaca-se ainda que as organizações oficias de turismo nos três destinos analisados figuram como uma entidade responsável pela imagem e pela propaganda de uma imagem e/ou forjam uma marca para que os turistas conheçam a localidade, no sentido de despertar a vontade de visitar o destino.

Diferente do que pode ser observado nas análises relativas aos materiais institucionais, as operadoras e agências de turismo direcionam seu foco e mensagens comunicativas no ato de publicizar a imagem do destino, isto é, colocar o destino à venda (Kotler, 2000). As operadoras utilizam estratégias semelhantes para a divulgação dos destinos em suas páginas (imagens e textos), contudo sua finalidade é vender a localidade. Sendo assim, as operadoras criam um ambiente sugestivo para que o turista se encante, mas também compre seu produto/serviço em forma de pacote (Muniz, 2004).

Tal dinâmica incorre principalmente na forma em que as informações são apresentadas pela iniciativa privada. Ao analisar o conjunto de elementos e informações em seus materiais publicitários e prints, notou-se que havia um direcionamento comunicativo nas informações (e.g. passeio de compras, completo de lazer etc.). Um exemplo deste direcionamento pode ser observado nas figuras $3 \mathrm{e}$ 4, referentes as operadoras de viagens X e Y. Mudanças também foram encontradas na linguagem e no conteúdo dos textos utilizados pelo trade. Enquanto nas organizações públicas o texto era apresentado em uma linguagem formal (intuito de instruir/informar), nas empresas privadas o texto foi apresentado em um tom informal (despertar interesse/convencer), quase como um convite ou conversa descontraída, estratégia característica do discurso publicitário (Vignati, 2005).

A presença de elementos relativos ao preço dos pacotes foi um dos pontos de destaque nas imagens e textos analisados. Apesar de muitos tarifários serem mostrados somente ao final da compra, sua presença é um claro indicativo de comercialização.

Apesar de existir um intuito explícito na questão da venda por parte das operadoras, notou-se que o caráter do discurso publicitário (publicidades) é reafirmado pela forma com que estas empresas moldam seus textos e imagens, isto é, colocando em primeiro plano informações e indicações relativas ao seu produto.

A localidade é apresentada de acordo com a lógica promocional de um produto manufaturado. Destacam-se qualidades, possíveis utilizações e benefícios que aquilo acarretará ao seu comprador (Kotler et al., 2007; Middleton \& Clarke, 2002). 
Figura 3: Print Pacote Foz do Iguaçu - Operadora X

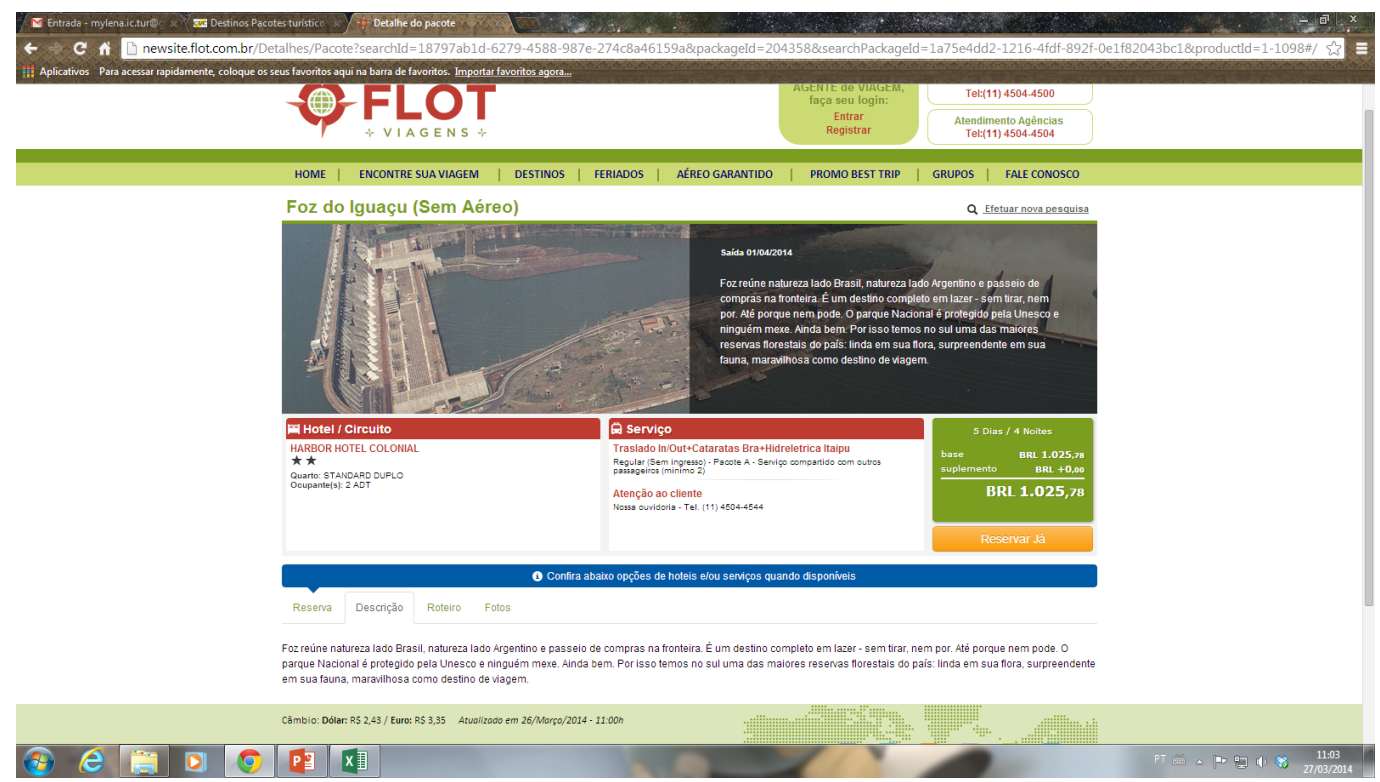

Fonte: Dados da pesquisa (2013)

Figura 4: Print Operadora Y - Ilha do Mel

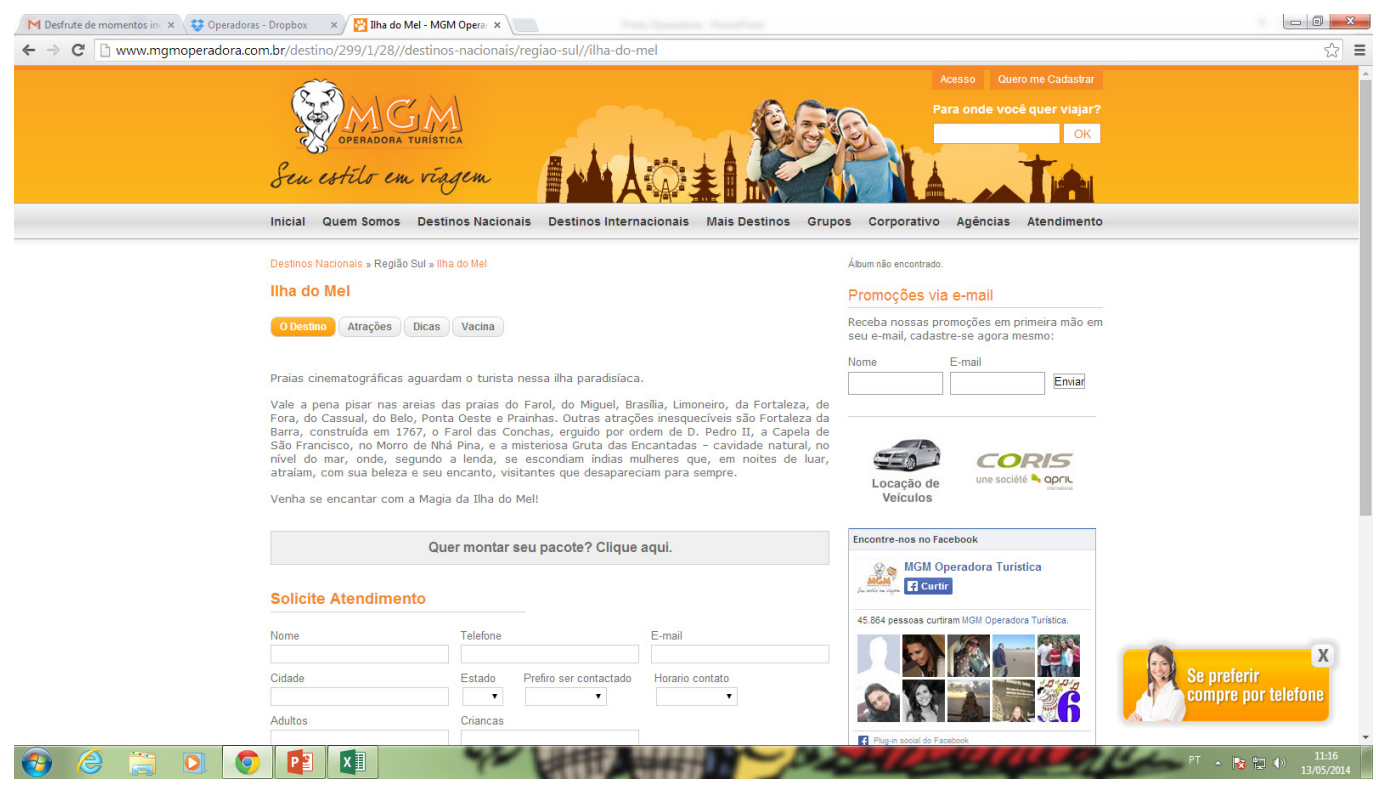

Fonte: Dados da pesquisa (2013)

A partir dos conceitos estudados, e procurando aplicar os conceitos de publicidade e a propaganda dentro do processo de comunicação de localidades, construiu-se a representação seguinte (Figura 5). Parte-se do pressuposto de que, a localidade pode ser comunicada de duas formas diferentes frente ao prisma em que for colocada, ou seja, para a as organizações públicas oficiais como um destino turístico e para a iniciativa privada um produto turístico. 
Figura 1: Comunicando a localidade como destino turístico e como produto turístico

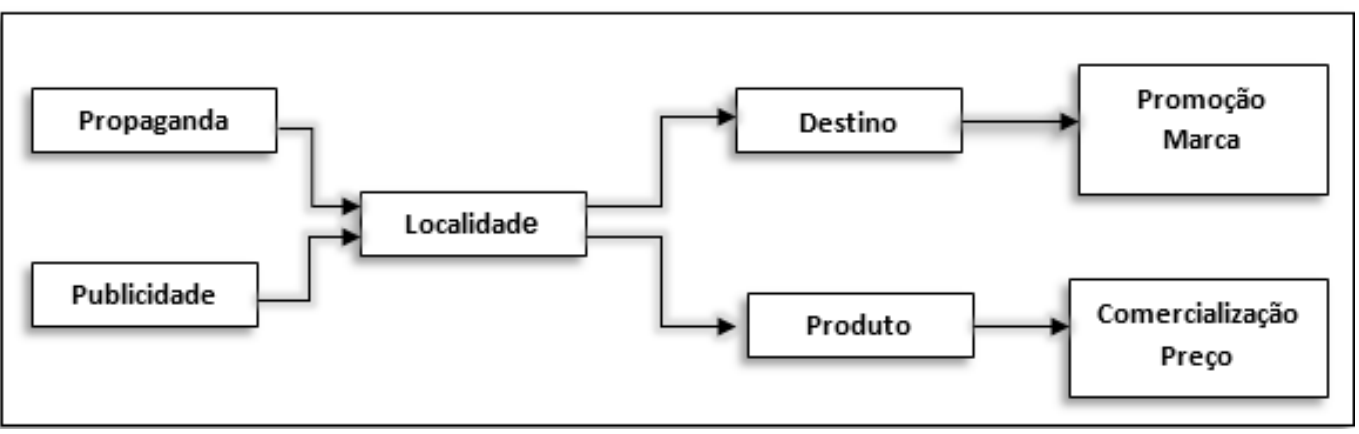

Fonte: Os autores (2016)

Sendo assim, foi possível observar a aplicação do conceitos de publicidade e propaganda a partir do aporte da revisão de literatura e da confirmação a partir dos materiais promocionais analisados. Demonstrou-se que, há diferenças nas ações de comunicação de uma localidade como destino e como produto turístico, bem como no entendimento da promoção e da promoção e comercialização de localidades.

Em relação aos agentes envolvidos nesse processo, verifica-se a presença dos organismos oficias de turismo como propagadores da ideia da localidade como um destino turístico, assim, "[...] a promoção corresponde ao esforço de comunicação que é normalmente dirigido pelo setor público para divulgar a imagem e a oferta de um destino turístico[...]" (Vignati, 2005, p. 276). Já a iniciativa privada considera o uso da publicidade a fim de promover e, principalmente comercializar (ou seja, vender) fazendo com que a localidade se configure em um produto turístico, passível de precificação.

\section{Conclusão}

A distinção entre as ações de comunicação ligadas aos organismos oficias de turismo e à iniciativa privada foi considerada por meio do estudo dos materiais institucionais e das ações de promoção veiculadas online

Dessa forma, foi possível, dentro do estudo, realizar duas constatações e contribuições para o uso do marketing e da comunicação no turismo. Primeiro, quando olhamos para uma a localidade como destino, a promoção da imagem desta localidade apresenta alguns pontos a serem destacados tais como: valor social, criação de uma imagem institucional e foco na atração dos turistas, caracterizando assim o processo de propaganda ou de propagação de ideias.

Essas três diretrizes puderam ser observadas nos destinos analisados. quando colocadas em detrimento com o conceito de produto turístico. Segundo, as ações de comunicação da iniciativa privada (caracterizada como publicidade) destacam a localidade como um produto comercializável, ou seja, passível de venda e por isso configurando outro enfoque de promoção, que destaca pontos como: anúncios publicitários voltadas ao mercado, precificação, utilização da imagem institucional criada pelo poder público e foco na venda do produto, uma vez que, 
o destino e seus atrativos se tornam produtos nas prateleiras das agências e operadoras de turismo.

Com efeito, entende-se que o foco desta investigação e a sua principal contribuição estiveram relacionadas ao estabelecimento da diferença entre a comunicação da localidade como destino turístico ou como produto turístico, por meio da aplicação dos conceitos de publicidade e propaganda e da análise dos materiais institucionais e não institucionais. Pontuando ainda diferenças nos conceitos de promoção e, de promoção e comercialização da localidade.

No que tange ao estado do Paraná e as cidades analisadas Curitiba, Foz do Iguaçu e Paranaguá, pode-se dizer que a promoção institucional, ou seja, a promoção da localidade como destino turístico ainda não é abrangente o suficiente para atrair os turistas para as localidades somente para fins de visitação. Foi constatado que, o que atrai os turistas para os destinos é a imagem institucional que promove e os anúncios publicitários que comercializam o que as localidades construíram ao longo dos anos, sendo destacável características como as Cataratas em Foz do Iguaçu, o planejamento e a qualidade de vida em Curitiba e a historicidade e meio ambiente por trás de Paranaguá configurando um roteiro de visitação (Morretes, Antonina e Ilha do Mel).

No caso das operadoras, o foco é voltado para os serviços oferecidos e os pacotes, assim as informações relacionadas a localidade figuram em segundo plano. Em conjunto com outras entidades comerciais as operadoras vendem os três destinos de forma diferente, dando maior enfoque publicitário a Foz do Iguaçu, um destino que se apresenta mais consolidado no mercado que os demais (Curitiba e Paranaguá), a cidade de Curitiba não tem tanto enfoque por parte das operadoras, e Paranaguá é promovida em segundo plano, capitaneada pelas ações publicitárias feitas para a Ilha do Mel. Além disso, Foz do Iguaçu é o destino com maior promoção entre os três abordados neste estudo, assim, o município tem maior destaque em folders e se apresenta como um destino mais acessível e visível. Já Curitiba e Paranaguá/Ilha do Mel não são tão promovidos e comercializados pela iniciativa privada, mas quando são, apresentam informações detalhadas.

Por fim é possível afirmar que uma localidade pode ser vista de dois modos, pela ótica da propaganda ou pelo viés da publicidade, sendo configurada como um destino turístico para fins de propaganda e como um produto turístico pela publicidade. Inicialmente este trabalho pautava-se na compreensão da diferença entre ações de promoção de uma localidade a partir dos materiais promocionais de organizações oficiais de turismo e do trade turístico, no entanto, a partir da revisão de literatura, notou-se que além da diferença entre esse processo de promoção, existe também uma diferença entre a aplicação de conceitos (publicidade e propaganda) do marketing na visão de cada um dos agentes responsáveis pela promoção do destino.

Deste modo, reforça-se a ideia da propaganda e da publicidade explicitadas por Gomes (2011). Onde a localidade como um produto turístico apresenta as seguintes características: 1) passível de comercialização, 2) promovida pelo trade/iniciativa privada, 3) passível de precificação e 4) atrelado à publicidade. Já a localidade como um destino turístico apresenta as seguintes características: 1) passível de promoção, 2) promovida pelas organizações oficiais de turismo, 3) comunicada como uma ideia/experiência/marca (atribui-se a ideia de valor a experiência e não ao dinheiro), 4) atrelada ao conceito de propaganda. 
Assim, é possível identificar que essas diferenças conceituais, se apresentam na prática quando se analisam os materiais promocionais de cada agente envolvido na comunicação de uma localidade. Porém, apesar desta diferença, e pensando em um eixo principal entre a publicidade e a propaganda, onde o marketing é o elemento chave para essa promoção e comercialização, a localidade como um destino não pensa sua propaganda voltada somente para os turistas e visitantes, sua comunicação também tem enfoque aos demais públicos, tais como, empreendedores, investidores, comunidade local e intermediários. Destaca-se também a partir deste estudo que no processo de comunicação e promoção turística ainda existe uma polarização de ações entre organismos públicos e empresas privadas (em especial no contexto brasileiro) quando se discute as formas como a localidade pode/deve ser promovida e comercializada.

\section{REFERÊNCIAS}

Almeida, A. L. de C. (2005) A influência da identidade projetada na reputação organizacional. 361f. Tese (Doutorado em Administração) - Curso de Pós-Graduação em Pesquisas em Administração, Universidade Federal de Minas Gerais, Belo Horizonte.

Bardin, L. (2011) Análise de conteúdo. São Paulo: Edições 70.

BRASIL. Ministério do Turismo, Secretaria Nacional de Políticas de Turismo, Departamento de Estruturação, Articulação e Ordenamento Turístico, Coordenação Geral de Segmentação. (2006). Segmentação do turismo: Marcos conceituais. Brasília: Ministério do Turismo.

Costa, C. C. M., Soares, B. S. \& Emmendoerfer, M. L. (2011). Análise da relação entre desejos turísticos e condições socioeconômicas de destinos no Brasil. Administração Pública e Gestão Social, 3(3), 165-185.

Corner, D. M. (2001). Introdução ao Turismo. Roca, São Paulo.

Cooper, C., Fletcher, J., Gilbert, D. \& Wanhill, S. (2007). Turismo: princípios e práticas, Trad.: Salvaterra, A, Porto Alegre: Bookman.

Chias, J. (2005). El negocio de la felicidad. 28. ed. Madrid: Pearson Educación.

Cruz, G., Gonçalvez, S., Mendes.S Filho, S.E \& Santos, W.B.V. (2008). Promoção de destinos: um olhar ético cultural sobre as operadoras turísticas. In: ANPTUR: Seminário Anual da Associação Nacional de Pesquisa e Pós-Graduação em Turismo, 5, Belo Horizonte. Anais... 1-15. Disponível em: <http://www.uesc.br/icer/artigos/promocao_destinos. pdf>. Acesso em: 27 out. 2013.

Denker, A. (2001). Pesquisa em Turismo: planejamento, métodos e técnicas. 5 ed. São Paulo: Futura.

Echtner, C. M. \& Ritchie, J.R.B. (2003). The meaning and measurement of Destination Image. The Journal of Tourism Studies. [S.I], 14 (1):37- 48.

EMBRATUR; Instituto Brasileiro de Turismo. (2003). Plano Aquarela 2003-2006. Brasília: Embratur.

Gândara, J. M. G. (2008). Imagem de Destinos Turísticos Urbanos. Revista Eletrônica de Turismo Cultural, São Paulo, Número Especial.

Giancomini Filho, G. (1998). A publicidade do turismo no contexto da competitividade. Turismo - Visão e Ação, 1(1): 61-73.

Gomes, N. D. (2001). Publicidade ou propaganda? É isso aí! Revista Famecos, 16:111-121. 
Guardani, F., Aruca, J. \& Araujo, M. (1996). Comportamento do Consumidor e a Escolha das Destinações Turísticas. Turismo em Análise,7(2):17-27, 20.

IBGE, Instituto Brasileiro de Geografia e Estatística. (2016). Noções básicas de cartografia: Localidade, 2016. Disponível em: goo.gl/Xj4s1t. Acesso em: 13 jun., 2016.

Kotler, P. (2000). Administração de marketing, 10ª Edição. São Paulo: Prentice.

Kotler, P., Gertner, D., Rein, I. \& Haider, D. H. (2007). Marketing de lugares. São Paulo: Prentice Hall.

Loda, M. D., Norman, W. \& Backman, K. F. (2007). Advertising and publicity: suggested new applications for tourism marketers. Journal of Travel Research, 45:259-265.

Madeira, N. (2010). Marketing e comercialização de produtos e destinos. Editora Princípia Lda. Porto.

Marques, P. A. A importância dos grandes eventos na promoção da imagem e consolidação dos destinos turísticos. 2005. 231f. Dissertação (Mestrado em Gestão e Desenvolvimento em Turismo) - Curso de Pós-Graduação em Gestão e Engenharia Industrial, Universidade de Aveiro, Portugal.

Marques De Sousa, R. \& Massukado-Nakatani, M. S. (2015). A promoção de Miami, FL/ EUA como destino turístico a partir da identificação e descrição de papéis dos atores públicos e privados envolvidos no planejamento e gestão de marketing da localidade. Anais... Seminário da Associação Nacional de Pesquisa e Pós-Graduação em Turismo (ANPTUR), Natal, RN, Brasil, 12.

Middleton, V. T. C. \& Clarke, J. (2002). Marketing de turismo: Teoria e Prática. (3a ed.). Rio de Janeiro: Campus.

Morrison, A. M. (2013). Marketing and managing tourism destinations. New York: Routledge.

Muniz, E. (2004). Publicidade e propaganda: Origens históricas. Cadernos Universitários, n. 148.

Neves, A. T. (2007). Promoção turística - 0 impacto das parcerias entre agentes públicos e privados. 2007. 344f. Dissertação (Mestrado em Gestão e Desenvolvimento em Turismo) - Curso de Pós-Graduação em Economia, Gestão e Engenharia Industrial, Universidade de Aveiro, Portugal.

Nunes Júnior, V. S. (2001). Publicidade comercial: proteção e limites na Constituição de 1988. São Paulo: Juarez de Oliveira.

Organização Mundial Do Turismo. (2001). Introdução ao turismo. São Paulo: Roca.

Petroski, T. A. B., Baptista, P. P. \& Maffezzolli, E. C. F. (2013). Personalidade de cidades e marketing de lugares. Turismo em Análise, 24(1):4-24.

Pimentel, E., Pinho, T. \& Vieira, A. (2006). Imagem da Marca de Um destino Turístico. Turismo Visão e Ação, 8(2):283-289.

Qu, H., Kim, L. H. \& Im, H. H. (2010). A model of destination branding: Integrating the concepts of the branding and destination image. Tourism Management, 2(32):465-476.

Rabaça, C. A. \& Barbosa, G. (1987). Dicionário de comunicação. São Paulo: Ática.

Sandmann, A. (2007). A linguagem da propaganda. (9a ed.). São Paulo: Contexto.

SERVIÇO BRASILEIRO DE APOIO ÀS MICRO E PEQUENAS EMPRESAS (Sebrae). (2008). Brasil: Guia de cidade. Brasília: CNC; Sebrae.

Scótolo, D. \& Panosso-Netto, A. P. (2014). Contribuições do turismo para o desenvolvimento local. Cultur, 1(9):36-59. 
Timón, D. A. B. (2004). El concepto de destino turístico: una aproximación geográfico-territorial. Estudios Turísticos,160: 45-68.

Vignati, F. (2008). Gestão de destinos turísticos: Como atrair pessoas para polos, cidades e países. Rio de Janeiro/RJ: Ed. Senac Rio.

Recebido em: 07/12/2016

Aprovado em: 29/05/2017

\section{CONTRIBUiçÃo}

Marcia Shizue Massukado Nakatani: idefinição do problema de pesquisa e

OBJETIVOS; DESENVOLVIMENTO DA PROPOSIÇÃO TEÓRICA; ESCOLHA DOS PROCEDIMENTOS METODOLÓGICOS; ANÁLISE DE DADOS; ELABORAÇ̃̃o DE TABELAS, GRÁFICOS E FIGURAS; REVISÃo CRÍTICA DO MANUSCRITO; REDAÇÃO DO MANUSCRITO.

Ewerton Lemos Gomes: REALIZAÇ̃̃̃o DA REVISÃo BIBLIOGRÁFICA E FUNDAMENTAÇÃo TEÓRICA; EsColHa dos PROCEDIMENTOS METOdolóGICOS; ColetA DE DADOS; ANÁLISE DE DADOS; ELABORAÇão DE TABELAS, GRÁFICOS E FIGURAS; REVISÃo CRítICA DO MANUSCRITO; REDAÇão Do MANUSCRITO; AdEQUAÇÃo DO MANUSCRITO ÀS NORMAS DA RTA.

Mylena Palazzo Nunes: Desenvolvimento da Proposição teórica; ReALizaÇão da REVISÃo

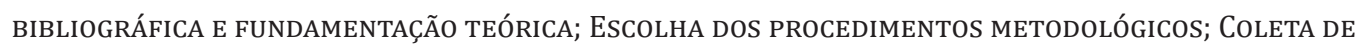
DADOS; ANÁLISE DE DADOS; ElABORAÇÃo dE TABELAS, GRÁFICOS E FIGURAS. 